\title{
Words of the Editor-in-Chief some ideas about the comments and discussions of hyperpycnal flows and hyperpycnites
}

\author{
Zeng-Zhao Feng
}

\begin{abstract}
I basically agree with the viewpoints of Shanmugam (Journal of Palaeogeography 7(3):197-238, 2018) and Zavala (Journal of Palaeogeography 8(3), 2019) who cited, refined and interpreted the definitions of hypopycnal flow, homopycnal flow and hyperpycnal flow. I appreciate two typical case studies of hyperpycnal flows induced by the Yellow River and Yangtze River, and the Gaoping River. The former is a normal type while the latter is catastrophic. They make up a complete knowledge about hyperpycnal flows and hyperpycnites. According to the interpretation of the word "hyperpycnal" from Greek to English, the "hypopycnal flow" should be "less density flow" or "lower density flow" ("低密度流"), the "homopycnal flow" should be "equal density flow" ("等密度流"), and the "hyperpycnal flow" should be "higher density flow" or "over density flow" ("高密度流" or “超密度流"). Some geologists called the "hypopycnal flow" as "异轻流" ("abnormally light flow") and called the "hyperpycnal flow" as "异重流" ("abnormally heavy flow"). There are at least more than 10 names or terms about the "density flows" and the "deposits of density flows". It is a problem indeed. In addition, the density could be changed by salinity, temperature and pressure of water. Therefore, the term "density flow" may be problematic either. Another problem is that reliable and irrefutable identification markers of ancient heperpycnites are lacking. We should observe the policy of "A hundred flowers blossom and a hundred schools of thought contend" to discuss these problems and to promote progress and development of hyperpycnal flows and hyperpycnites.
\end{abstract}

Keywords: Hyperpycnal flows, Hyperpycnites, Density flows, Definitions and names of density flows and their deposits, Identification markers of ancient hyperpycnites, A hundred flowers blossom and a hundred schools of thought contend

This paper presents my ideas about "The hyperpycnite problem" by Shanmugam (2018) and the comment papers by Zavala (2019) "The new knowledge is written on sedimentary rocks - a comment on Shanmugam's paper "the hyperpycnite problem"' and by van Loon et al. (2019) "the hyperpycnite problem: comment". It means that the problems of hyperpycnal flows and hyperpycnites are an interesting and a hot subject which attracts much attention of geologists.

I, as the Editor-in-Chief of the Journal of Palaeogeography, observe the policy of "A hundred flowers blossom and a hundred schools of thought contend", write this paper, and hope to discuss these problems and to promote progress and development of hyperpycnal flows and

Correspondence: jpalaeo2012@163.com

China University of Petroleum (Beijing), Beijing 100083, China hyperpycnites. I heartily welcome geologists to participate in this discussion and to get some common views.

\section{About the paper by Shanmugam (2018)}

The paper by Shanmugam (2018) is a comprehensive statement of hyperpycnites and hyperpycnal flows. I especially agree with the following 3 points of his paper.

Firstly, Shanmugam cited and refined the concepts of Bates (1953) in his Fig. 2 and interpreted: (a) Hypopycnal plume in which the density of river water is less than the density of basin water; (b) Homopycnal plume in which the density of river water is equal to the density of basin water; and (c) Hyperpycnal plume in which the density of river water is greater than the density of basin water. He defined (c) hyperpycnal plume as hyperpycnal 
flow and the deposits of hyperpycnal flow as hyperpycnites.

I agree with these definitions.

Secondly, Shanmugam described the hyperpycnal flows and their deposits generated by the Yellow River and the Yangtze River in detail. He considered that terrestrial clastic materials can not be transported across the continental shelf to deep sea by hyperpycnal flow.

I think that Shanmugam's data of hyperpycnal flows induced by the Yellow River and the Yangtze River are reliable and his statements are rational.

Thirdly, Shanmugam in the Table 1 of his paper cited a number of case studies of density plumes (Table 1 in his paper) and distinguished the hyperpycnal flow from turbidity current and river current, etc. It is beneficial to readers.

Certainly, Shanmugam's paper (2018) has some shortcomings.

\section{About the paper by Zavala (2019)}

\subsection{Hyperpycnal flow in Gaoping River}

Zavala (2019) proposed 10 questions about Shanmugam's paper (2018). Here, I only discuss the first and second question, because these two questions are very important.

The first question is that the hyperpycnal flow in Gaoping River (Gaoping Canyon), SW Taiwan, China, transported enormous terrestrial clastic materials to deep sea.

I have carefully read the papers (Liu et al. 2012; Liu et al. 2016; Chiang and Yu 2008). According to my understanding the Gaoping River (Gaoping Canyon) has the following characteristics.

It is a short mountainous river with down-cutting canyon which has an average gradient of 1:150 and links the river catchment to deep sea. In addition, the geological setting and climatic conditions in SW Taiwan, China, such as earthquakes, typhoons, floods, further promote the river flow and related hyperpycnal flow to transport enormous clastic materials, including coarse grains, to deep sea.

These characteristics of Gaoping River are significantly different from those of the Yellow River and Yangtze River. The Yellow River and Yangtze River are long and large-scale rivers. Their geological settings are broad platforms, i.e., North China Platform and Yangtze platform. Their transported clastic materials at their river mouths are fine-grained clasts, mainly silt and mud. The continental shelf of the Yellow River and Yangtze River is a broad shelf. Therefore, the hyperpycnal flows induced by the Yellow River and Yangtze River are impossible to transport terrestrial clastic materials, especially coarse grains, to deep sea. Shanmugam (2018) further emphasized that the hyperpycnal flows induced by Yellow River and Yangtze River and their deposits in deep- water setting (i.e., seaward of the shelf-slope break at about $200 \mathrm{~m}$ water depth, Fig. 3), are highly speculative.

In a word, the hyperpycnal flows induced by the Yellow River and Yangtze River and their deposits, and the hyperpycnal flow induced by the Gaoping River and its deposits, are two typical and significantly different case studies. The former is a normal type while the latter is catastrophic. I think these two case studies will make up a complete knowledge about deposits of hyperpycnal flows and hyperpycnites. I especially appreciate these two case studies.

\subsection{Definition of hyperpycnal flow}

The second question of Zavala (2019) about Shanmugam's paper (2018) is "the origin of hyperpycnal flow". In fact, it is the definition of hyperpycnal flow.

Zavala (2019) and Zavala and Pan (2018a, b), as the same to Shanmugam (2018), also cited and refined the concepts and Fig. 3 of Bates (1953) in Fig. 1 of Zavala and Pan (2018a, b). They also defined and interpreted: (A) Hypopycnal flow in which the density of incoming flow is less or lower than the density of receiving water body; (B) Homopycnal flow in which the density of incoming flow is equal to the density of receiving water body; (C) Hyperpycnal flow in which the density of incoming flow is greater or higher than the density of receiving water body.

Zavala (2019) and Zavala and Pan (2018a, b) further interpreted the meaning of the word "hyperpycnal" from Greek to English, i.e., "hyper" means "over" and "pycnal" means "density".

According to this interpretation, the "hypopycnal flow" in which the density of incoming flow < the density of receiving water should be "less density flow" or "lower density flow"; the "homopycnal flow" in which the density of incoming flow = the density of receiving water should be "equal density flow"; and the "hyperpycnal flow" in which the density of incoming flow > the density of receiving water should be "over density flow" or "higher density flow".

According to the definitions of the above 3 terms, the Chinese translated name of "hypopycnal flow" should be “低密度流” ("lower density flow" or "less density flow"); the Chinese translated name of "homopycnal flow" should be “等密度流” ("equal density flow"); and the Chinese translated name of "hyperpycnal flow" should be “高密度流” or “超密度流” (“higher density flow” or "over density flow").

However, in the Chinese version of Zavala and Pan (2018a, b), the Chinese translated name of "hypopycnal flow" is "异轻流” (it means "abnormally light flow"), and the Chinese translated name of "hyperpycnal flow" is “异 重流" (it means "abnormally heavy flow"). 
The two Chinese translated names “异轻流” and “异重 流" are not true to the original meaning of the English names. I disagree with using these two Chinese translated names.

Yang et al. (2017b) based on mud contents and gravity flows' origination, divided the gravity flow into 4 types, i.e., slumps, debris flows, turbidity currents and hyperpycnal flows, and called the hyperpycnal flow as “异重流”. I disagree with using this Chinese translated name either.

It is a problem for geologists, especially for Chinese geologists, to be discussed carefully.

\section{Two essential problems}

There are two essential problems in hyperpycnal flows and hyperpycnites, i.e., the definitions of hyperpycnal flows and hyperpycnites and the identification markers of ancient hyperpycnites.

\subsection{About the definitions of hyperpycnal flows and hyperpycnites}

About the definitions of hyperpycnal flows and hyperpycnites, my ideas are as follows. (1) I basically agree with the definitions of Bates (1953) and the interpretations of Shanmugam (2018), Zavala (2019), and Zavala and Pan $(2018 \mathrm{a}, \mathrm{b})$, i.e., the "hypopycnal flow in which the density of river water < the density of basin water" is "lower density flow"; the "homopycnal flow" in which the density of river water $=$ the density of basin water is "equal density flow"; and the "hyperpycnal flow" in which the density of river water $>$ the density of basin water is "higher density flow" or "over density flow". (2) The names of "lower density flow", "equal density flow", "higher density flow" or "over density flow" are better than "hypopycnal flow", "homopycnal flow" and "hyperpycnal flow", i.e., the English names are better than the foreign original names sourced from Greek, because the English names are very clear and very easy to understand. (3) I agree with the Chinese translated terms “低 密度流” ("lower density flow" or "less density flow"), “等 密度流” (“equal density flow”), and “高密度流” ("higher density flow" or "over density flow"). (4) I disagree with the Chinese translated terms “异轻流” and “异重流” translated by Zavala and Pan (2018a, b), because the two Chinese translated terms are not true to the original meanings of English terms. (5) If the translators Zavala and Pan and other Chinese geologists considered that these two Chinese terms are suitable, they would be better to write a new paper explaining them in detail.

Confucius said: “名不正则言不顺, 言不顺则事不成”. It means that "if the name is not right, then the speech will not be in order; if speech is not in order, then nothing will be accomplished". Therefore, the correct definitions of hyperpycnal flows and hyperpycnites are essential problems which should be solved firstly.

\subsection{About the identification markers of ancient hyperpycnites}

Nowadays, the case studies of modern hyperpycnal flows and hyperpycnal deposits are plentiful enough, please refer to the papers of Shanmugam (2018), Zavala (2019) and Zavala and Pan (2018a, b) and the references of the 3 papers. However, the studies of ancient hyperpycnites, i.e., the papers of hyperpycnites in geological history with reliable and irrefutable identification markers are relatively rare. It is another essential problem.

For example, the "criteria for identifying hyperpycnites" in the "YC 7 oil member of the Yanchang Formation of the Late Triassic Ordos Basin, central China" are lacking reliable and irrefutable evidence. Please refer to Yang et al. (2017a).

My ideas are as follows. (1) Firstly, the "10 oil members of the Yanchang Formation" are not "10 members" of the Yanchang Formation, but "10 oil-bearing intervals" of the Yanchang Formation. In Yanchang Formation, there are 5 stratigraphic members. Therefore, the "10 members" should be "10 oil-bearing intervals" and the "YC 7 oil member" or "seventh oil member" should be "seventh oil-bearing interval" of the Yanchang Formation. Please refer to Deng et al. (2011) and Feng et al. (2013). (2) The small rhythmic changes of upward coarsening layers and upward finning layers which consist of very fine sandstones, siltstones and shales in 7th oilbearing interval of the Yanchang Formation may be formed due to multiple origins. The sedimentary period of the 7th oil-bearing interval was the time of the largest-scale lake transgression during the sedimentary period of Yanchang Formation. Any small fluctuation of the lake level could induce the small rhythmic changes of upward coarsening and upward finning layers of very fine sandstones, siltstones and shales. The hyperpycnites may not be the only interpretation of the small rhythmic changes. (3) Yang et al. (2017b) in their "Summary and conclusions" indicated "hyperpycnites developed together with debris and turbidites" in the 7th oil-bearing interval of the Yanchang Formation. However, Yang et al. (2017b) did not point out the reliable identification markers of debris and turbidites respectively either.

\section{About the discussions of the Chinese translated names of hyperpycnal flows and hyperpycnites}

\subsection{About the comments of 3 Chinese reviewers}

3 Chinese reviewers made comments on the Chinese translated names of hyperpycnal flows of my paper.

Prof. Wang Zhanghua agreed with my Chinese translated name of “hyperpycnal flow" as “超密度流”, because it is easy to understand. 
Prof. Wang Yaping considered that the hyperpycnal flows and hyperpycnites are very interesting in the Earth sciences community, especially for geologists. Till now, many issues are still unclear on this topic. He also said: If we utilize "higher density flow" to replace "hyperpycnal flow", it would make confusion, because the density could be changed by salinity, temperature and pressue. ..... The term "over density flow" is better but may not be accurate. For me, personally, I prefer the term “异重流” in Chinese, which is already widely accepted by Chinese resercheres in sediment dynamics and estuarine-coasted sciences.

Prof. Fan Daidu said: "Lower density flow" and "higher density flow" should not replace "hypopycnal flow" and "hyperpycnal flow". The Chinese names “异轻流” and “异 重流" are accurate to represent the original meanings of Bates (1953). These two Chinese names are crystallization of wisdom of Chinese academic and engineering domains. These two Chinese names are not created by Zavala and Pan (2018a, b).

In a word, the above comments of Chinese reviewers illustrate different viewpoints of the definitions and names of hyperpycnal flows both in English and Chinese.

In my mind, there are numerous names or terms of density flows, i.e., "hypopycnal flow", "homopycnal flow" and "hyperpycnal flow" (in fact, they are foreign terms from Greek); "less density flow" or "lower density flow"; "equal density flow"; "higher density flow" or "over density flow" (in fact, these terms are English terms); and corresponding Chinese translated terms “低密度流” or “异轻流”, “等密度流”, “高密度流” or “超密度流” or “异重流”。

About the deposits of density flows, there may be the same number of corresponding terms or names of "density flows".

There are so many names or terms about the "density flows" and the "deposits of density flows". It is a serious problem indeed!

We should observe the policy of "A hundred flowers blossom and a hundred schools of thought contend" and set up a scientific theme to discuss these problems. It is an effective measure to promote progress and development of hyperpycnal flows and hyperpycnites.

Now, as a Chairman of Academic Committee of the $4^{\text {th }}$ ICP and the Editor-in-Chief of the Journal of Palaeogeography, I heartily invite Profs. Wang Zhanghua, Wang Yaping, Fan Diadu, Shanmugam, Zavala, and other geologists to write papers, attend the $4^{\text {th }}$ ICP (if possible), and participate in this discussion and strive to get some common views about the definitions and their names of hyperpycnal flows and hyperpycnites, both English names and their Chinese translated names proposed by Chinese geologists.
Certainly, I also hope some geologists can write papers about another essential problem, i.e., the identification markers of ancient hyperpycnites.

\subsection{A suggestion}

I have never researched the hyperpycnal flows and hyperpycnites. I hardly know this academic topic before reading these papers submitted to Journal of Palaeogeography. However, I am the Editor-in-Chief of Journal of Palaeogeography, and I have to know the basic knowledge of this topic. It is a hard task for me. At the beginning, I was always troubled by these numerous terms and their meanings of hypopycnal flow, homopycnal flow, hyperpycnal flow, etc. In the process of reading these papers of Profs. Shanmugam and Zavala and the references of many authors, I gradually understood their original meanings, i.e., they are different "density flows".

I agree with Prof. Wang Yaping's idea "the density could be changed by salinity, temperature and pressure of water ......". Therefore, the term "density flow" itself may be a problematic term either.

It may be suitable to utilize " $\mathrm{xx} \mathrm{kg}$ clastics $/ 1 \mathrm{~m}^{3}$ water" or "xx g clastics / $1 \mathrm{dm}^{3}$ water", i.e., to utilize the " $\mathrm{xx} \%$ " or "0.xx\%" of content of clastics to express "density"?

Now, I cited a poem of Su Dongpo, a great master of literature in Song Dynasty:

不识庐山真面目，只缘身在此山中 (One does not recognize the true features of Lushan, only because he is in this mountain).

It means that if we desire to recognize the true features of Lushan, we should stand outside of Lushan, i.e., if we desire to understand the true features of hyperpycnal flows and hyperpycnites, we should jump out of the old viewpoints and utilize new philosophical thinking pattern to recognize them.

Certainly, it may be a layman's suggestion. I hope experts of this domain can think of it.

\section{Brief conclusions}

1) Many thanks to Profs. Shanmugam and Zavala since they pointed out many important problems about hyperpycnal flows and hyperpycnites. A thorough discussion about these problems, especially the above two essential problems may bring out theoretical innovations for hyperpycnal flows and hyperpycnites.

2) However, no further academic discussions regarding papers by Shanmugam (2018), Zavala (2019) and van Loon et al. (2019), will be considered for publication in the Journal of Palaeogeography (Shanmugam 2019).

3) Xi (2016) said: "All theoretical innovation starts with specific problems. The course of theoretical 
innovation is, in a sense, the course of identifying, winnowing, researching and eventually solving problems." It means that theoretical innovation can only be started from problems (Feng 2018).

4) I hope that the above two essential problems can attract attention of geologists worldwide, including Chinese geologists, and that they are willing to write papers about these essential problems, to clearly define and complete the definitions and names both in English and Chinese of hyperpycnal flows and hyperpycnites, to provide the reliable and irrefutable identification markers of ancient hyperpycnites, and to make theoretical innovations for hyperpycnal flows and ancient hyperpycnites.

5) The Journal of Palaeogeography heartily welcomes geologists to submit papers about the definitions of hyperpycnal flows and relevant flows, and papers about ancient hyperpycnites with reliable identification markers.

\begin{abstract}
Acknowledgements
I heartily thank Wang Yuan, an Associate Editor-in-Chief of the Editorial Office of Journal of Palaeogeography. She carefully corrected and polished this manuscript. I especially thank the reviewers, Profs. Shanmugam, Zavala, Wang Zhanghua, Wang Yaping and Fan Daidu. They corrected and polished this manuscript and made many comments to it. The section 4 "About the discussions of the names of hypercnal flows and hyperpycnites" was composed mainly on their comments and enlightenment.
\end{abstract}

\section{Authors' contributions}

ZZF wrote the article and approved the final version of the manuscript.

Funding

No funding has been provided to the author for the present contribution.

\section{Competing interests}

The author declares that he has no competing interests.

Received: 4 April 2019 Accepted: 27 May 2019

Published online: 01 July 2019

\section{References}

Bates, Charles C. 1953. Rational theory of delta formation. Bulletin of the American Association of Petroleum Geologists 37 (9): 2119-2162.

Chiang, C.C., and H.S. Yu. 2008. Evidence of hyperpycnal flows at the head of the meandering Kaoping canyon off SW Taiwan. Geo-Marine Letters 28: $161-169$

Deng, X.Q., J.H. Fu, J.L. Yao, J.L. Pang, and B. Sun. 2011. Sedimentary facies of the middle-upper Triassic Yanchang formation in Ordos Basin and breakthrough in petroleum exploration. Journal of Palaeogeography (Chinese Edition) 13 (4): 443-455 (in Chinese with English abstract).

Feng, Z.Z. 2018. Theoretical innovation can only be started from problem: Reply to comments of 3 review papers. China Terminology 20 (6): 47-49 (in Chinese with English abstract).

Feng, Z.Z., Bao, H.P., Jia, J.H., Wang, Y.G., Deng, X.Q. 2013. Lithofacies palaeogeography as a guide to petroleum exploration. In: Feng, Z.Z. (Chief Editor). Sedimentology of China, 2nd Edition, 2. 1760-1792. Chapter 30. (in Chinese with English preface and contents).

Liu, J.T., R.T. Hsu, J.J. Hung, Y.P. Chang, Y.H. Wang, R.H. Rendle-Bühuring, C.L. Lee, C.A. Huh, and R.J. Yang. 2016. From the highest to the deeper: The Gaoping River-Gaoping submarine canyon dispersal system. EarthScience Reviews 153 (2016): 274-300.
Liu, J.T., Y.H. Wang, R.J. Yang, R.T. Hsu, S.T. Kao, H.L. Lin, and F.H. Kuo. 2012. Cyclone-induced hyperpycnal turbidity currents. Journal of Geophysical Research 117 (CO4033): 1-12.

Shanmugam, G. 2018. The hyperpycnite problem. Journal of Palaeogeography 7 (3): 197-238.

Shanmugam, G. 2019. Reply to discussions by Zavala (2019) and by Van Loon, Hüeneke, and Mulder (2019) on Shanmugam (2018). Journal of Palaeogeography 8 (3).

Van Loon, A.J., H. Hüneke, and T. Mulder. 2019. The hyperpycnite problem: Comment. Journal of Palaeogeography 8 (3).

Xi, J.P. 2016. Develop philosophy and social sciences with Chinese features. In: XI JINPING, The Governace of China, II. 366-377. Beijing: Foreign Language Press.

Yang, R.C., Z.J. Jin, A.J. Van Loon, Z.Z. Han, and A.P. Fan. 2017b. Climatic and tectonic controls of lacustrine hyperpycnite origination in the late Triassic Ordos Basin, Central China: Implications for unconventional petroleum development. AAPG Bulletin 101 (1): 95-117.

Yang, R.C., W. Yin, A.P. Fan, Z.Z. Han, and A.J. Van Loon. 2017a. Fine-grained, lacustrine gravity-flow deposits and their hyper hydrocarbon significance in the Triassic Yanchang formation in southern Ordos Basin. Journal of Palaeogeography (Chinese Edition) 19 (5): 791-806 in Chinese with English abstract.

Zavala, C. 2019. The new knowledge is written on sedimentary rocks - A comment on Shanmugam's paper "the hyperpycnite problem". Journal of Palaeogeography 8 (3).

Zavala, C., and S.X. Pan. 2018a. Hyperpycnal flows and hyperpycnites: Origin and distinctive characteristic. Lithologic Reservoirs 30 (1): 1-27.

Zavala, C., and S.X. Pan. 2018b. Chinese version of "Hyperpycnal flows and hyperpycnites: Origin and distinctive characteristics". Lithologic Reservoirs 30 (1): 1-18 (in Chinese).

\section{Publisher's Note}

Springer Nature remains neutral with regard to jurisdictional claims in published maps and institutional affiliations.

\section{Submit your manuscript to a SpringerOpen ${ }^{\circ}$ journal and benefit from:}

- Convenient online submission

- Rigorous peer review

- Open access: articles freely available online

High visibility within the field

- Retaining the copyright to your article

Submit your next manuscript at $\boldsymbol{\nabla}$ springeropen.com 